\title{
Non-Fickian Absorption Characteristics of Adhesive Joints: Capillary Effects and Residual Properties
}

\author{
Mahzan Johar, Wong King Jye ${ }^{*}$, Mohd Nasir Tamin \\ School of Mechanical Engineering, Universiti Teknologi Malaysia, 81310 Johor Bahru, Malaysia.
}

Received 24 April 2018; accepted 27 August 2018, available online 31 October 2018

\begin{abstract}
Mechanical performance of polymer-based adhesive joints is generally susceptible to moisture absorption. This study quantifies the effects of moisture content on the strength, stiffness, and energy properties of adhesive bonded joints. For this purpose, moisture absorption characteristics of structural adhesive joints (Araldite $2015)$ with different thicknesses $(0.5,1.0$, and $1.5 \mathrm{~mm})$ were firstly established under accelerated aging condition (deionized water at $60{ }^{\circ} \mathrm{C}$ ). A thickness-dependent non-Fickian moisture absorption model was then used to characterize the moisture absorption of the adhesive joints. Results suggested that the moisture absorption of the adhesive joints was governed by the capillary action. Subsequently, adhesive joints with aluminum 6061 adherent and $0.5 \mathrm{~mm}$-thick Araldite 2015 adhesive compound were subjected to dry, $0.1,0.15,0.18$, and 0.2 pct of moisture content. The specimens were tested in shear and tension loadings at $1 \mathrm{~mm} / \mathrm{min}$. The resulting variations in the mechanical properties were fitted using a residual property model. It was noticed that all properties degraded upon moisture attack. For strength and energy properties, the degradation was more severe in tension. As for the stiffness, the decrease in the property was similar in both tensile and shear. The results from this study showed that moisture attack is an important aspect to be considered when designing for the service lifetime of adhesive bonded structures.
\end{abstract}

Keywords: Adhesive joints, moisture absorption, non-Fickian, thickness-dependent, residual property model

\section{Introduction}

Material joining is a fundamental technology in manufacturing where designers have the selections of joining technique such as riveting, bolting, welding, and adhesive joint [1]. Adhesively bonded joints has been particularly well established in industries that require joining thin or dissimilar materials to provide higher stiffness and more uniform load distribution in structural parts than their mechanical fastening counterparts. In this respects, adhesives are designed to have strong bonding to meet demands from various industries applications.

The applications of adhesive are extend from low to high strength demanding structures. Its application can be found in manufacturing miniature products and high strength to weight ratio components such as composite laminates and honeycomb structures that used in aircraft. Adhesive technology and its application will continue to grow due to versatility and capability for application in various industries such as construction, aerospace, packaging, and automotive.

During the service lifetime of the adhesively bonded joint structures, the absorbed moisture from the environment may degrade the adhesive joints through hygroscopic expansion, plasticization, and swelling in the adhesive. This could degrade the performance of the joints and lead to premature failure of the structures. Hence, it is of paramount importance to understand the moisture absorption behavior in the adhesive joints and its influences on the mechanical properties of the joints [2].

In characterizing the moisture uptake behavior in polymeric materials, the non-Fickian behavior is quite commonly observed. Non-Fickian is an indication of retarded water molecules penetration. Consequently, even with accelerated tests in the laboratory, the amount of time needed for the absorbed moisture to reach saturation is still comparatively long. Hence, a thickness-dependent model has been previously proposed to predict the moisture absorption behavior in the relatively thick polymer-based materials using thinner specimens [3]

In addition, considering structural adhesive joints that are generally subjected to complex loadings, the tensile and shear tests are the two most fundamental loading conditions to be investigated. In adhesive joints, the cohesive, adhesive, and mixed-mode failures are commonly observed. The difference in the failure modes signifies the different crack propagation and energy dissipation processes and are essential to be evaluated as well.

Currently, a common method of evaluating joint performance in general loading under humid environment and temperature effects is by doing experimental testing in the laboratory. Experimental testing in the laboratory is costly and time-consuming, especially when adhesive performance over a long period of time is to be determined. This types of testing contradicts with the 
industrial environment, where the minimization of cost and short lead times to be their priority.

The environmental effects on adhesively bonded joints have been attract a great attention from researches [4-8]. The mechanical performance of adhesively bonded joints have a significant affected when exposed to aqueous environments, especially at elevated temperatures. The fracture toughness could reduce up to $92 \%$ and the locus of failure changes from cohesive to adhesive failure for dry to wet environment, respectively [9]. The mechanical properties of adhesively bonded steel/epoxy joints for yield stress and tensile modulus decrease as aging time increases [10]. A double cantilever beam specimen of adhesively bonded joint displayed different mechanical properties at varying combination of absorbed moisture and temperature [6]. The aged specimens exhibit lower fracture toughness and suffered adhesive failure when tested at room temperature and $80^{\circ} \mathrm{C}$. However, cohesive failure was observed at $-40{ }^{\circ} \mathrm{C}$ Similar finding of the effect of temperature on mechanical properties of adhesively bonded basalt FRPaluminum alloy joints have been established [11].

The first objective of the present work is to quantify the water ingression behavior in the adhesive bonded joints as a function of adhesive thicknesses. The second objective is to characterize the variation of the strength, stiffness, and energy of the adhesive joints at various absorbed moisture contents under both tensile and shear loadings. The corresponding failure modes of the adhesive joint are identified.

\section{Material and Experimental Procedure}

\subsection{Characterization of Moisture Absorption}

The moisture absorption of adhesive joints was determined by gravimetric test. Prior to the moisture absorption test, the adhesive joints were dried in an oven at $50{ }^{\circ} \mathrm{C}$ for 12 hours followed by the measurement of the dry weight after cooling down to room temperature. Three different thicknesses $(0.5,1.0$ and $1.5 \mathrm{~mm})$ are examined to establish the moisture absorption characteristics of the structural adhesive joints under accelerated aging condition (deionized water at $60^{\circ} \mathrm{C}$ ).

Measurement was taken out periodically to record the weight of the specimens and the corresponding exposure time until the moisture uptake saturation is reached. The adhesive joints specimens for moisture absorption test as shown in Fig. 1. A Mettler Toledo electronic balance with $0.1 \mathrm{mg}$ accuracy was used to weigh the samples at predetermined time intervals of the aging period.

\subsection{Sample preparation}

The adhesive studied (Araldite 2015) was purchased from Huntsman Advanced Materials. Table 1 summarizes properties of the adhesive used in this work. The adhesive joint was designed into a circular shape with a diameter of $25.4 \mathrm{~mm}$. The bonded surfaces of aluminum adherent were sandblasted with a \#100 $\mu \mathrm{m}$ particle with the resulting in nominal surface roughness value of $5.26 \mu \mathrm{m}$ which was measured using Mitutoyo portable surface roughness probe. The surfaces were then degreased with acetone prior to the bonding process. A $0.5 \mathrm{~mm}$ thickness spacer was used to ensure a uniform bond thickness. According to manufacturer's specification, a constant pressure of $2 \mathrm{MPa}$ was applied for 15 seconds to the adhesive joints and cured in an oven for 2 hours at $50{ }^{\circ} \mathrm{C}$.

Then, the specimens were left at room temperature for 24 hours prior testing. Moisture-absorbed specimens are immersed in a water bath at $60{ }^{\circ} \mathrm{C}$ for a specified time duration to have $0.1,0.15,0.18$ and $0.2 \%$ moisture content.

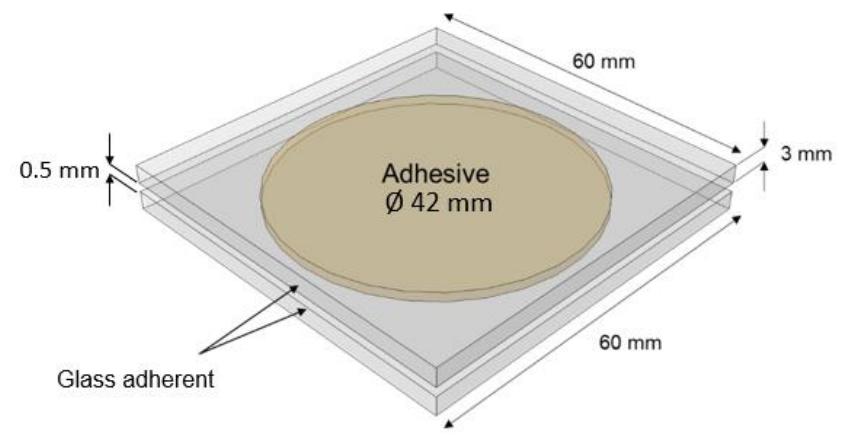

Fig. 1 Adhesive joint specimen for moisture absorption test

Table 1 Mechanical Properties of Araldite 2015 [12

\begin{tabular}{lc}
\multicolumn{1}{c}{ Property } & Value \\
Young's modulus, $E[\mathrm{GPa}]$ & $1.85 \pm 0.21$ \\
Poisson's ratio, $v$ & $*$ \\
Tensile yield strength, $\sigma y[\mathrm{MPa}]$ & 0.33 \\
Tensile failure strength, $\sigma f[\mathrm{MPa}]$ & $21.63 \pm 0.61$ \\
Tensile failure strain, $\varepsilon_{\mathrm{f}}[\%]$ & $4.77 \pm 0.15$ \\
Shear modulus, $G[\mathrm{GPa}]$ & $0.56 \pm 0.21$ \\
Shear yield strength, $\tau_{\mathrm{y}}[\mathrm{MPa}]$ & $14.6 \pm 1.3$ \\
Shear failure strength, $\tau_{\mathrm{f}}[\mathrm{MPa}]$ & $17.9 \pm 1.8$ \\
Shear failure strain, $\gamma_{\mathrm{f}}[\%]$ & $43.9 \pm 3.4$
\end{tabular}

\subsection{Test procedures}

The tests are performed in laboratory air at room temperature using INSTRON 5982 electromechanical testing machine with a $5 \mathrm{kN}$ load cell. A modified Arcan jig was used to apply the tensile and shear loading to the specimens with crosshead displacement speed of 1 $\mathrm{mm} / \mathrm{min}$.

The schematic of adhesively bonded joints and the experimental setup are shown in Fig. 2. The measured load-displacement response to failure of the adhesively bonded joints was recorded throughout the test.

\section{Results and Discussion}

Results are presented and discussed in terms of the characteristics of moisture uptake behavior at different thicknesses. The deformation response of the adhesive joints with different moisture content subjected under quasi-static tensile and shear loadings are deliberated. 


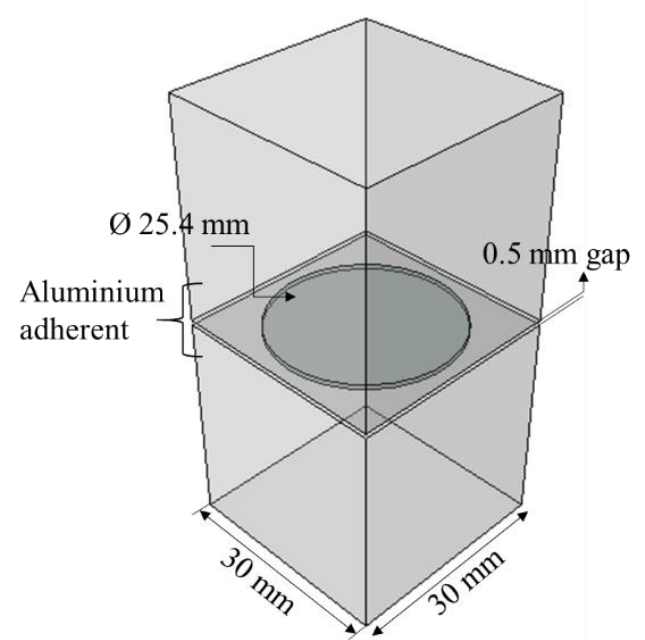

(a) Tensile loading $\left(0^{\circ}\right)$

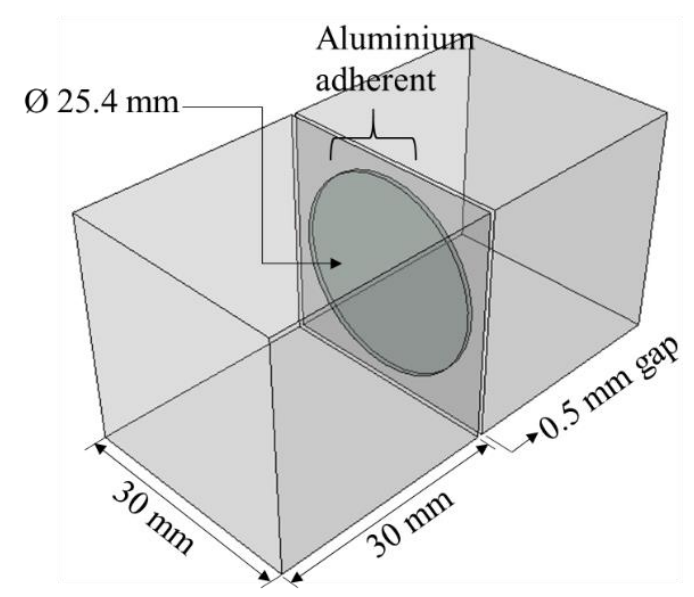

(b) Shear loading $\left(90^{\circ}\right)$

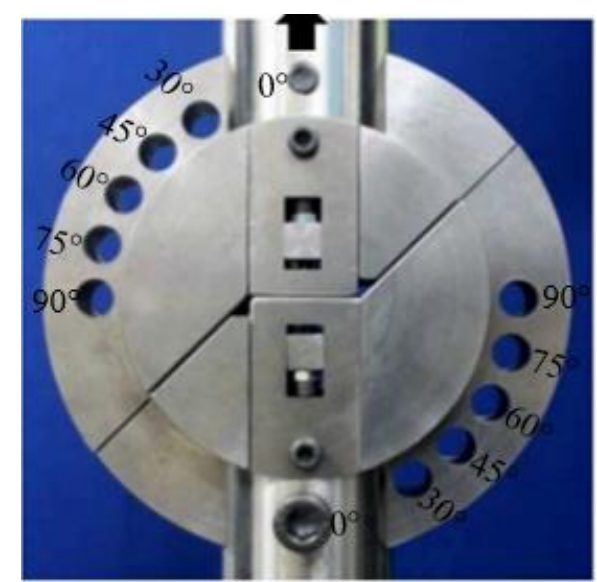

(c)

Fig. 2 Adhesively bonded specimen geometry under (a) tensile and (b) shear loadings; (c) modified Arcan jig setup for testing of the specimen.

\subsection{Characteristics of Moisture Uptake Behavior at Different Thicknesses}

Fig. 3 displays a typical moisture absorption behavior of the adhesive joints for the adhesive thicknesses of $0.5,1.0$ and $1.5 \mathrm{~mm}$. The error bars implied good reproducibility of experimental data at the respective moisture absorption level. Results indicated that a smaller thickness at $0.5 \mathrm{~mm}$ exhibits a greater moisture absorption per unit exposed area. This implied the non-Fickian moisture absorption behavior which was believed to be attributed to the capillary effect. It was postulated that at a smaller thickness, the surface tension at the adherent-adhesive interface was larger and has driven more water molecules into the system [13].

In addition, for the $1.5 \mathrm{~mm}$-thick adhesives, it was observed that the secondary absorption occurred. This is believed to be due to increased free volume due to microcracking that led to the new absorption sites. A similar observation has been found in FM73 rubber toughened epoxy adhesive [14].

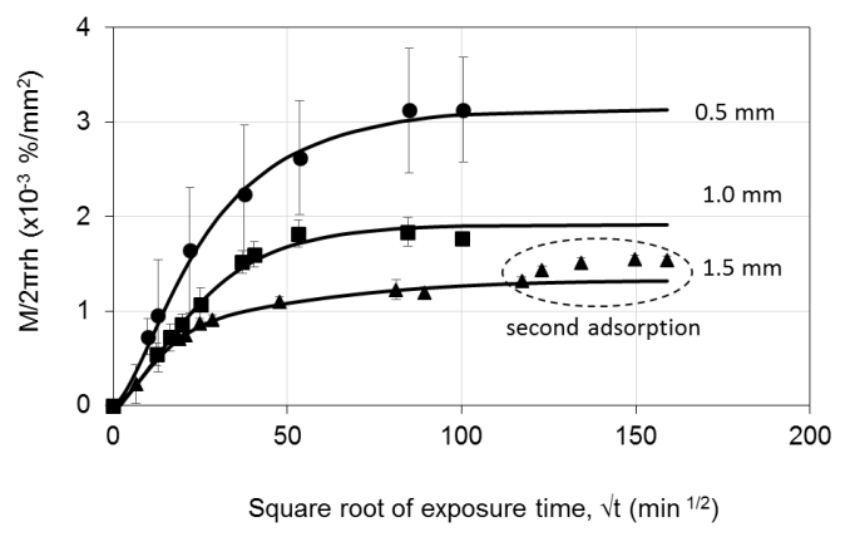

Fig. 3 Moisture uptake behavior of the adhesive bonded aluminum joints at different thicknesses

\subsection{Effects of Quasi-Static Loading on Adhesive Joint under Moisture Condition}

The measured load-displacement response for the adhesive joints at various moisture contents under tensile and shear loadings are shown in Fig. 4. For both tensile and shear loadings, it could be seen that all curves decreased linearly at the initial stage, followed by a sudden load drop after the peak load was attained. In general, it was observed that the stiffness and failure load decreased with increased moisture content. As moisture content increased, the adhesive material becomes softer. This is consistent with the observation by other researchers $[10,15]$.

In order to characterize the variation of mechanical properties of the adhesive joints tested due to moisture absorption, the residual property model (RPM) proposed by Wong et al. [16] is adopted. RPM describes that the normalized residual property can be predicted using the following equation:

$$
\frac{P_{r}}{P_{o}}=1-(1-s)\left(\frac{M}{M_{m}}\right)^{\zeta}
$$

Where $P_{r}$ is the residual property at particular moisture content, $P_{o}$ is the dry property, $s$ is the ratio of the 
residual property at saturation to the dry level, $M$ is the moisture content, $M_{m}$ is the saturation of moisture content, and $\zeta$ is the degradation parameter. The degradation parameter, $(\zeta>1)$ is when the degradation parameter shows linearly increase with moisture content, $(\zeta=1)$ is when the degradation parameter relatively stable with ageing and $(\zeta<1)$ is when the degradation parameter shows more sensitive to the moisture attack.

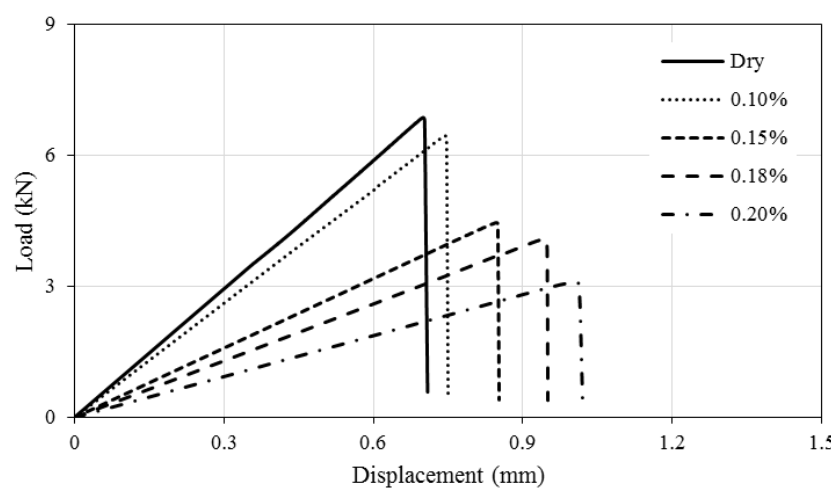

(a)

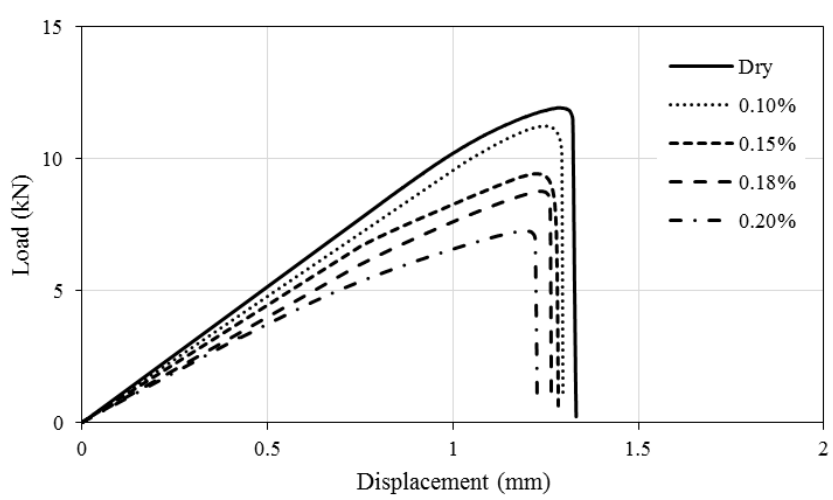

(b)

Fig. 4: Load-displacement response for (a) tensile (b) shear loadings under different moisture contents and quasi-static condition.

Subsequently, the variation of the mechanical properties of the adhesive joints with respect to the absorbed moisture content was compared. Referring to Fig. 5, it was noticed that all properties (strength, energy, and stiffness) degraded with the increase in moisture content. This was consistent with the general observation and all data was hence fitted using the residual property model (RPM) proposed previously by Wong et al. [16]. Results showed a good fit for the different properties considered. Reference property of the normalized value; (strength, energy and stiffness) for tensile loading is (17.66 MPa, 7151.38 N.mm and 8151.37 N/mm) and for shear loading is $(22.68 \mathrm{MPa}, 11494.52 \mathrm{~N} . \mathrm{mm}$ and $11494.52 \mathrm{~N} / \mathrm{mm})$, respectively.

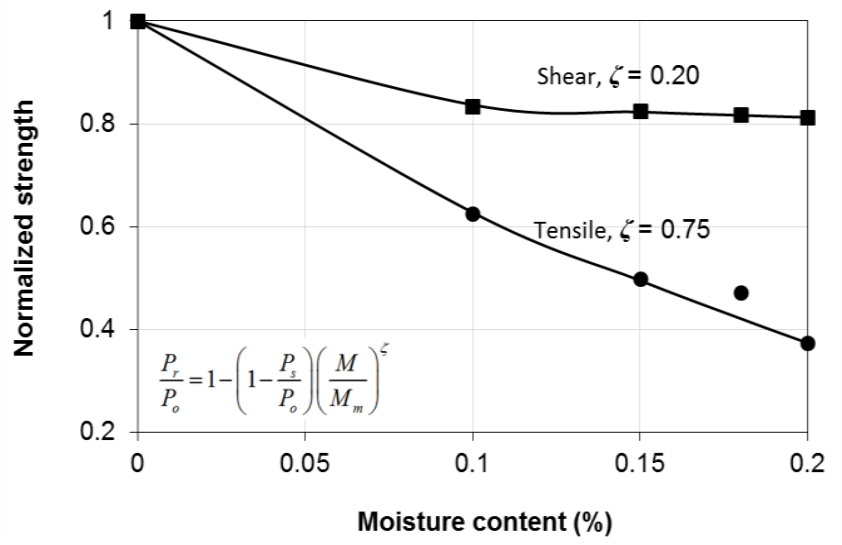

(a)

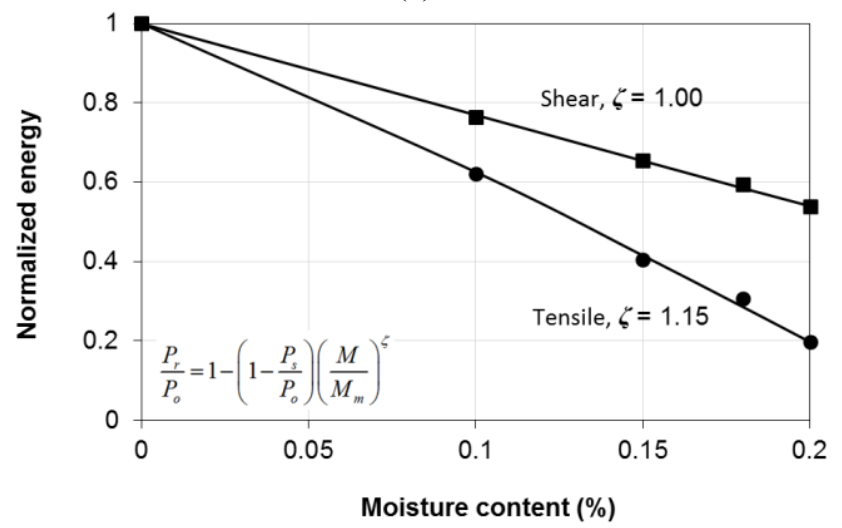

(b)

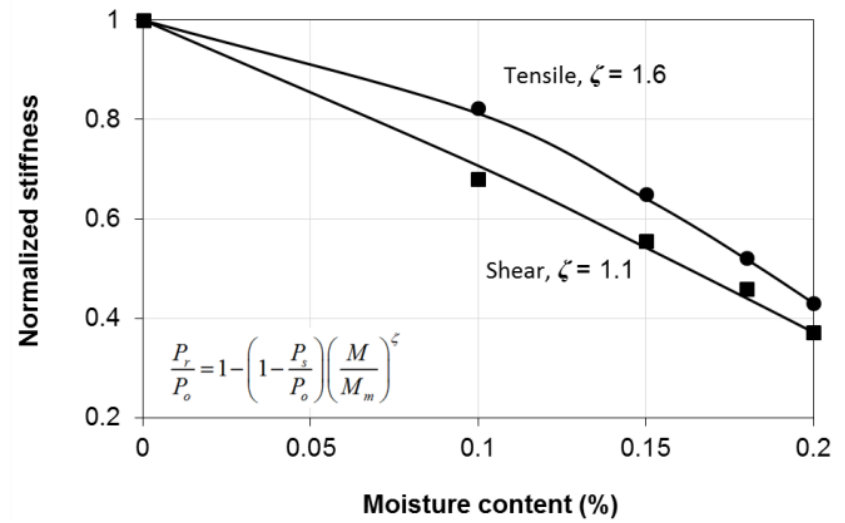

(c)

Fig. 5: Normalized (a) strength (b) energy (c) stiffness with respect to the moisture content.

\subsection{Failure Modes}

Adhesive or cohesive failure involves a crack extending within the bulk adhesive layer, while adhesive failure consists of a crack between the adherent/adhesive interface, as illustrated in Fig. 6. 
Adhesive failure

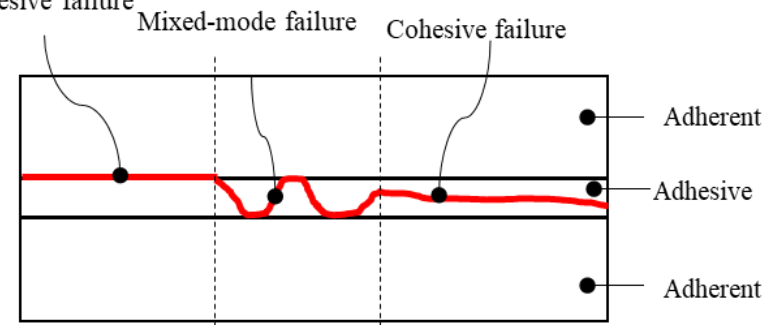

Fig. 6 Illustration of different failure mechanism of an adhesively bonded joints.

The failure mode of the adhesive joints is significantly depending on the moisture content. Fig. 7 and Fig. 8 illustrates the dominant mode of failure observed at different moisture contents. The fractured surface morphology was captured following the final failure. Mixed-mode, consisting of both adhesive and cohesive, failure dominates in both loading conditions. This is believed to be attributed to the degradation of the adhesive, where moisture ingression has caused plasticization of the adhesive [14].

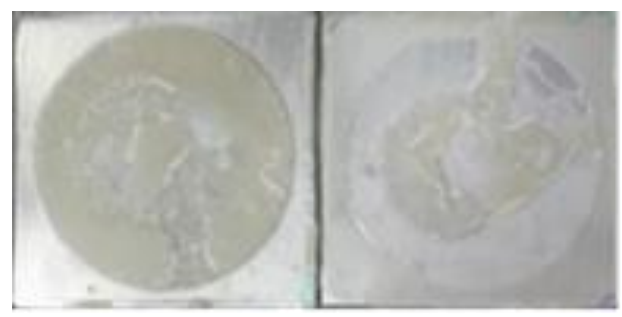

(a) Dry

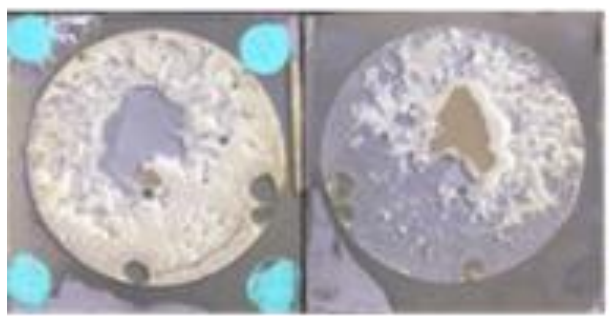

(b) $0.1 \%$ moisture absorption

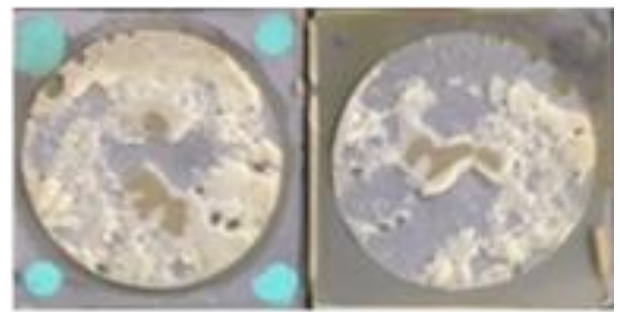

(c) $0.2 \%$ absorption

Fig. 7: The fracture surfaces of specimens after testing for tensile loading.

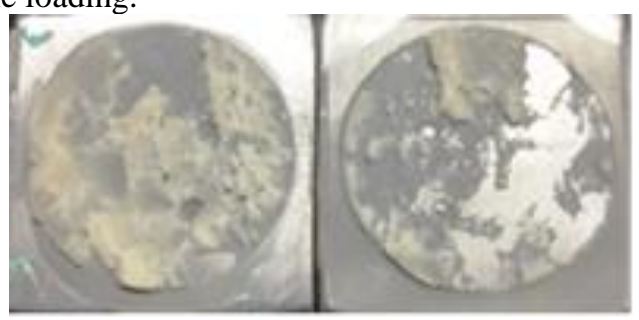

(a) Dry

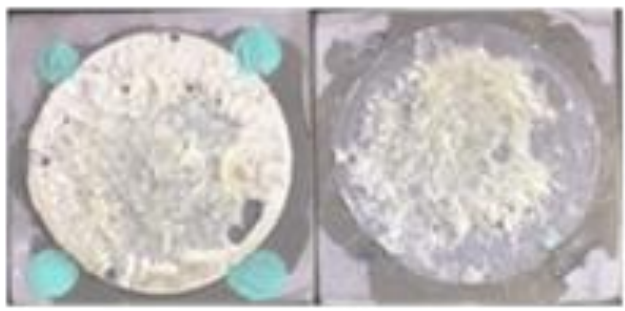

(b) $0.1 \%$ moisture absorption

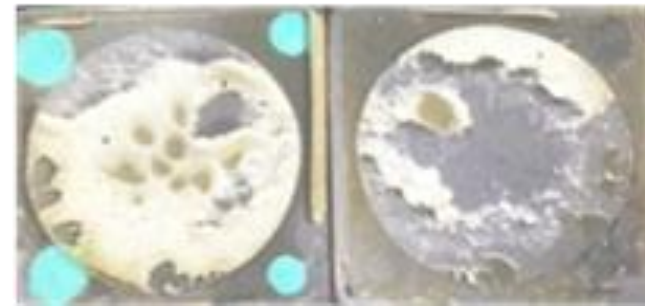

(c) $0.2 \%$ moisture absorption

Fig. 8: The fracture surfaces of specimens after testing for shear loading.

\section{Conclusions}

The moisture absorption characteristics and the influence of moisture content on adhesively bonded joints have been investigated experimentally. Based on the findings, the following conclusions are drawn:

- Moisture absorption in adhesive joints was governed by the capillary action and was hence thicknessdependent.

- For both tensile and shear loading conditions, all examined mechanical properties of the adhesive joints were degraded upon moisture attack; Property degradation (strength, energy, and stiffness) for tensile loading is $(62 \%, 80 \%$ and $55 \%)$ and for shear is $(20 \%, 42 \%$ and $62 \%)$, respectively.

- Strength and energy property were more sensitive to moisture attack under tensile loading, whereas, for the stiffness, both loadings showed similar degradation characteristic.

- Mixed-mode failure dominates under tensile and shear loadings at all moisture levels.

\section{Acknowledgement}

This work is supported by the Aerospace Malaysia Innovation Center (AMIC) through contract research grant No. 4C089 and Universiti Teknologi Malaysia (UTM) through matching grant No. 01M01.

\section{References}

[1] Ahmad, M.H., Crocombe, A.D., and Smith, P.A. Failure modelling of woven GFRP bolted joints under quasi-static loading. International Journal of Integrated Engineering, Vol. 5, 2013, pp. 32-36.

[2] Shamshuddin, M.K., Abdullah, M.E., and Shah, S.R. The development of moisture sensitivity test for compacted asphalt. International Journal of Integrated Engineering, Vol. 2, 2010, pp. 17-25. 
[3] Wong, K.J., Low, K.O, Israr, H.A, and Tamin, M.N., Thickness-dependent non-Fickian moisture absorption in epoxy molding compounds. Microelectronics Reliability, Vol. 65, 2016, pp. 160-166.

[4] Banea, M.D., da Silva, L.F.M., and Campilho, R. Mode I fracture toughness of adhesively bonded joints as a function of temperature: experimental and numerical study. International Journal of Adhesion and Adhesives, Vol.31, 2011, pp. 273279.

[5] Banea, M.D., da Silva, L.F.M., and Campilho, R. Mode II fracture toughness of adhesively bonded joints as a function of temperature: experimental and numerical study. The Journal of Adhesion, Vol. 88, 2012, pp. 534-555.

[6] Viana, G., Costa, Banea, M.D., and da Silva, L.F.M., Moisture and temperature degradation of double cantilever beam adhesive joints. Journal of Adhesion Science and Technology, Vol. 31, 2017, pp. 1824-1838.

[7] Abdel Wahab, M., Crocombe, A., Beevers, A., and Ebtehaj. K. Coupled stress-diffusion analysis for durability study in adhesively bonded joints. International Journal of Adhesion and Adhesives, Vol. 2, 2002, pp. 61-73.

[8] Han, X., Crocombe, A., Anwar, S., and Hu, P. The strength prediction of adhesive single lap joints exposed to long term loading in a hostile environment. International Journal of Adhesion and Adhesives, Vol. 55, 2014, pp. 1-11.

[9] Kinloch, A.J. Adhesion and Adhesives: Science and Technology. Springer Science \& Business Media, 1987.

[10] Bordes, M., Davies, P., Cognard, J.Y., Sohier, L., Sauvant-Moynot, V., and Galy, J. Prediction of long term strength of adhesively bonded steel/epoxy joints in sea water, International journal of adhesion and adhesives, Vol. 292009 pp. 595-608.

[11] Na, J., Mu, W., Qin, G., Tan, W., and Pu, L. Effect of temperature on the mechanical properties of adhesively bonded basalt FRP-aluminum alloy joints in the automotive industry, International Journal of Adhesion and Adhesives, Vol. 852018 pp. 138-148.

[12] Campilho, R., Banea, M.D., Neto, J., and Da Silva, L.F.M., Modelling of single-lap joints using cohesive zone models: effect of the cohesive parameters on the output of the simulations, The Journal of Adhesion, Vol. 882012 (4-6) pp. 513533.

[13] Zanni-Deffarges, M., and Shanahan, M. Diffusion of water into an epoxy adhesive: comparison between bulk behaviour and adhesive joints. International Journal of Adhesion and Adhesives, Vol. 15, 1995, pp. 137-142.

[14] Mubashar, A., Ashcroft, I.A., Critchlow, G.W., and Crocombe, A. Moisture absorption-desorption effects in adhesive joints. International Journal of
Adhesion and Adhesives, Vol. 29, 2009, pp. 751760.

[15] Hua, Y., Crocombe, A., Wahab, M., and Ashcroft, I. Continuum damage modelling of environmental degradation in joints bonded with EA9321 epoxy adhesive. International Journal of Adhesion and Adhesives, Vol. 28, 2008, pp. 302-313.

[16] Wong, K.J., Israr, H.A., and Tamin, M.N., Characterisation of moisture absorption effects on the strength of composite. Trans Tech Publication, 2015, pp. 69-73. 